\title{
A REPRESENTAÇÃO MÍTICA, SIMBÓLICA E FÍ́ICA DA MULHER INDÍGENA EM A CASA REDONDA, DE LOUISE ERDRICH
}

\author{
THE MYTHIC, SYMBOLIC AND PHYSICAL REPRESENTATION OF THE INDIGENOUS WOMAN IN THE ROUND \\ HOUSE, BY LOUISE ERDRICH
}

\section{RESUMO}

Uma das principais características da escrita de Louise Erdrich é a sua complexidade na narrativa familiar, política e social que são reflexos de anos de tumultuosas mudanças na história da comunidade indígena, tocando agudamente na injustiça histórica que está marcada em sua herança indígena. Aliada a essas características de suas obras, outro ponto marcante de sua escrita é a presença dos símbolos, que são elementos que possuem papel fundamental na literatura indígena. É por meio desses elementos simbólicos que esses povos constituem suas identidades e manifestam suas marcas culturais e espirituais. Todas essas marcas da escrita de Erdrich podem ser observadas na obra A Casa Redonda (2014), conforme veremos nesse artigo, cujo objetivo é estudar a imagem da mulher indígena em três dimensões: a dimensão social ou real, representada pela personagem Geraldine; a dimensão mítica ou da tradição, representada por Akii; e a dimensão simbólica, representada pela búfala.

Palavras-chave: Literatura Indígena. Louise Erdrich. A Casa Redonda. Mulheres do Terceiro Mundo.

\begin{abstract}
One of the main characteristics of Louise Erdrich's writing is its complexity in the family, political and social narrative that reflects years of tumultuous changes in the history of the indigenous community, touching sharply on the historical injustice that is marked on its indigenous heritage. Allied to these characteristics of his works, another striking point of his writing is the presence of symbols, which are elements that play a fundamental role in indigenous literature. It is through these symbolic elements that these peoples constitute their identities and manifest their cultural and spiritual marks. All these marks of Erdrich's writing can be seen in The Round House (2014), as we will see in this article, whose objective is to study the image of indigenous women in three dimensions: the social or real dimension, represented by the character Geraldine; the mythic or tradition dimension represented by Akii; and the symbolic dimension, represented by the buffalo.
\end{abstract}

Keywords: Indigenous Literature. Louise Erdrich. The Round House. Third World Women.

Me. Marcos Vinicius R. da Costa

Universidade Estadual de Maringá (UEM/Brasil). E-mail: marcosviniciuskosta@gmail.com

Dra Alba Krishna T. Feldman

Universidade Estadual de Maringá (UEM/Brasil). E-mail: profa.alba@gmail.com 
Louise Erdrich, que carrega heranças Chippewa do lado de sua mãe e germano-americana do lado de seu pai, se apresenta como um ótimo exemplo de identidade híbrida pós-colonial. As marcas desse hibridismo, que são reflexos de seu duplo contexto cultural, podem ser vistas em seus romances ao retratar personagens de identidades híbridas que são socialmente, culturalmente e territorialmente deslocados, vivendo nas reservas indígenas. Essas reservas são os habitats forçados dos indígenas estadunidenses, colocados para viver muitas vezes em condições miseráveis, cenários que aparecem frequentemente na ficção de Erdrich.

A autora tem se solidificado no cenário literário estadunidense como uma das escritoras mais influentes do Native American Renaissence ${ }^{1}$, pois suas contribuições para a representação da história dos indígenas estadunidenses são de fundamental importância, uma vez sua narração de Erdrich reconstrói um espaço para a cultura, a religião, a tradição dos indígenas estadunidenses e sua sobrevivência contínua. A busca por evidenciar e reafirmar o seu lugar no mundo tem sido uma questão significativa para os indígenas estadunidenses, o que, em suas escritas, traz a necessidade de redescobrir suas raízes históricas e culturais, representando sua história e cultura tanto para seus próprios descendentes, quanto para os não-indígenas. Assim, em seu desejo de construir uma identidade indígena estadunidense, Erdrich captura em seus trabalhos o terreno físico e social perdido por seu povo, chamando não apenas para uma identidade individual, mas para uma identidade tribal nacional. Assim, dentro dessa literatura de minoria étnica, busca-se, pelos escritores indígenas, uma identidade que integre uma sociedade, um passado, uma história e um lugar.

Podemos destacar, como uma das principais características dessa escrita de Erdrich, sua complexidade na narrativa familiar, política e social que são reflexos de anos de tumultuosas mudanças na história da comunidade indígena, tocando agudamente na injustiça histórica que está marcada em sua herança indígena. Aliada a essas características de suas obras, outro ponto marcante de sua escrita é a presença dos símbolos, que são elementos que possuem papel fundamental na literatura indígena. É por meio desses elementos simbólicos que esses povos constituem suas identidades e manifestam suas marcas culturais e espirituais. Todas essas marcas da escrita de Erdrich podem ser observadas na obra A Casa Redonda (2014), conforme veremos nesse artigo, cujo objetivo é estudar a imagem da mulher indígena em três dimensões, na obra $A$ casa Redonda (2014): a dimensão social ou real, representada pela personagem Geraldine; a dimensão mítica ou da tradição, representada por Akii; e a dimensão simbólica, representada pela búfala.

Diante de tal relevância, não podemos deixar de destacar a importância da escrita de Louise Erdrich, tendo em mente que ela é uma mulher pertencente a uma comunidade que, mesmo localizada em um país de primeiro mundo, ocupa a posição social de terceiro mundo. Segundo Ahmad (2002), o termo Terceiro Mundo é

1 Termo criado por Kenneth Lincoln em seu livro Native American Renaissance, de 1983, para descrever o aumento de produções e da de escritores indígenas estadunidenses a partir do final da década de 1960 em diante. O autor N. Scott Momaday é apontado como o primeiro a publicar, em 1968, seguido por Louise Erdrich, Paula Gunn Allen, Gerald Vizenor, entre outros. 
utilizado para descrever economicamente países subdesenvolvidos da Ásia, América Latina, África e Oceania. Esse conceito serve para identificar países que sofrem de alta mortalidade infantil, baixo desenvolvimento econômico, altos níveis de pobreza, baixa utilização de recursos naturais e analfabetismo. Diante dessas características, as populações de minorias, como as comunidades indígenas, podem ser consideradas, economicamente, de Terceiro Mundo, ainda que ocupem geograficamente uma posição de Primeiro Mundo. Nesse sentido, a literatura e as artes sempre foram um campo discursivo no qual os escritores expressaram os sentimentos humanos, suas contínuas lutas, principalmente contra aqueles que mantêm e perpetuam sua hegemonia cultural e política. Nesse contexto, as mulheres escritoras dessas comunidades étnicas do terceiro mundo estão conquistando seu espaço no cenário literário, evidenciando suas posições dentro dessa comunidade com uma renovada estética de expressão cultural e étnica. Com isso, elas abrem espaço para a denúncia dos silenciamentos presentes em suas vidas, e, principalmente, na constante violência sofrida diariamente por muitas delas, como é a história de Geraldine contada por Louise Erdrich em $A$ casa redonda

Segundo Anzaldúa (1981), em seu texto Speaking In Tongues: A Letter To 3rd World Women Writers, a autora destaca que os perigos enfrentados por essas mulheres do terceiro mundo não são os mesmos enfrentados por mulheres brancas, apesar de terem muito em comum. Para a autora mulheres do Terceiro Mundo "não temos muito a perder - nós nunca tivemos privilégios" (p.1)². Dessa forma, as escritas dessas autoras indígenas evidenciam um duplo preconceito enfrentado por elas: por serem mulheres e por serem indígenas.

Por isso, por meio deste artigo, buscamos analisar a narrativa de duas personagens femininas na obra A casa Redonda, de Louise Erdrich, em dois períodos históricos distintos e o modo como a história dessas duas mulheres representaram a história dos povos indígenas e a identidade da mulher indígena. Trata-se de Geraldine, a mãe do protagonista-narrador da história, Joe, e Akiikwe, a mulher mítica, mãe de Nanapush, além da figura feminina simbólica da búfala. A partir da circularidade dessas histórias indígenas, podemos destacar que esses fatos promovem a identificação da personagem com sua comunidade, uma vez que as imagens entre as duas histórias, Geraldine, e Akiikwe, sejam elas por suas semelhanças ou diferenças, permitem com que sua afirmação identitária e resistência possam acontecer. É por compreender a diversidade de significações dos símbolos, principalmente dos presentes nessas duas narrativas, auxiliados com o olhar para a história e manifestações culturais, que podemos observar o universo narrativo no qual estão inseridos as personagens femininas, e assim reconhecê-las como fonte de significados e sentidos, que, a partir de suas posições em relação ao referencial simbólico, evidenciará a sua função enquanto sujeitos culturais, reafirmando, assim, sua identidade e seu reconhecimento.

2 "We don't have as much to lose - we never had any privileges"(p.1). 


\section{A CASA REDONDA}

A Casa Redonda é uma história que tem seu espaço narrativo nas terras indígenas Chippewa, no estado de Dakota do Norte, no ano de 1988. Escrita em 11 capítulos, a história é narrada em primeira pessoa por Joe já na fase adulta, que relembra de seu passado, quando era apenas adolescente de 13 anos. A história registra seus sentimentos e ações diante de fatos devastadores que assolaram sua família e comunidade. Em uma linguagem coloquial, trazendo muitas vezes um tom lírico em sua escrita, Erdrich leva o leitor a compreender aspectos da cultura Chippewa com uma escrita que mescla humor, poeticidade, e uma profunda tristeza. É possível ver também em sua obra traços da oralidade, principalmente nas histórias contadas pelo avô de Joe, Joseph (Mooshum), enquanto dormia. Suas histórias recuperam o mito de Nanapush ${ }^{3}$. Uma das marcas de sua escrita, que vai ao oposto do que é visto na literatura ocidental, é um narrador que não apresenta onisciência dos fatos. Desse modo, Erdrich narra a história de um garoto que vê seu mundo modificado pela cruel violência sexual sofrida por sua mãe, Geraldine. Em meio à história, Erdrich faz uso de inúmeros símbolos presentes na mitologia e religiosidade indígena para nos mostrar as ligações presentes entre passado e presente dos povos indígenas.

Em um domingo qualquer na reserva, Joe e seu pai se ocupam da limpeza das plantas e mudas que invadiram a fundação de sua casa. Após um tempo, eles percebem que Geraldine, mãe de Joe e esposa de Bazil, ainda não retornou para casa. Ao perceberem essa situação atípica, eles decidem ir a sua procura, pois Geraldine sempre tinha o hábito de esquecer a chave presa dentro do carro. Imaginando tal possibilidade, eles vão ao seu encontro, e ao chegarem na estrada, Geraldine passa por eles com seu carro voltando para sua casa. Ao vê-la, eles sentem-se aliviados e retornam para a reserva. Ao chegarem lá, encontram Geraldine ainda em seu carro, sentada, com as mãos no volante, banhada a sangue, vômito e gasolina. Nesse momento Bazil percebe que algo está errado e leva sua esposa ao hospital, juntamente com seu filho, Joe. Ao chegarem ao hospital, Joe começa a perceber que sua mãe foi violentada, e que ele estava diante de uma situação que mudaria o rumo de sua vida.

Uma vez que Geraldine precisou passar alguns dias em uma clínica para repouso, após a descoberta de que Linden, o homem que a violentou, fora solto da prisão por falta de provas concretas de que o crime acontecera em terras indígenas, Joe é deixado para passar alguns dias na casa de sua tia Clemence, onde seu bisavô Joseph (Mooshum) mora. Sua tia lhe oferece o quarto de costuras para que possa dormir, mas ao olhar para as linhas e máquinas de costura, se lembra de que seu pai dormiu em um quarto semelhante em sua casa, e isso lhe traz sentimentos de

3 Nanapush - também conhecido por uma variedade de outros nomes, é uma figura brincalhona e heróica da cultura Anishinaabe, que aparece, principalmente, como o protagonista de um ciclo de histórias que fazem parte dos mitos de criação dos povos Anishinaabe. Essas histórias, particularmente dos Chippewa, bem como suas características, fazem de Nanapush uma das faces do Trickster. No estudo do folclore e da mitologia e da religião, Nanapush é um deus/deusa, sendo um espírito ou detentor de um corpo, um homem/mulher ou antropomórfico. 
como a união de seus pais estava estremecida com a violência sofrida por sua mãe. Dessa forma, ele decide, então, dormir no mesmo quarto que seu Mooshum, mesmo sendo alertado por sua tia de que ele falava enquanto dormia. Durante a noite, Joe acorda e ouve seu Mooshum pronunciando algumas palavras e cobre sua cabeça para voltar a dormir. Joe tenta dormir, mas é fisgado pelas palavras de seu Mooshum e percebe que "Mooshum não estava apenas falando aleatoriamente, como uma pessoa desconectada, soltando fragmentos da linguagem dos sonhos. Estava contando uma história" (ERDRICH, 2014, p.183).

Essas histórias de Mooshum durante o sono são antigas histórias Anishinaabe, que foram esquecidas por todos, menos pelos mais antigos da tribo, e que agora são ouvidas por Joe enquanto dorme no mesmo quarto que ele, um homem que estava "habitando uma névoa fora de seu tempo" (ERDRICH, 2014, p.10). Essa descrição do personagem representa, na obra, toda a tradição e memória do povo Anishinaabe que viveu em tempos distantes, mas com aspectos muito semelhantes a este.

Em seu sonho Joseph (Mooshum) narra a história de uma mulher Anishinaabe chamada $\mathrm{Akii}^{4}$, "uma mulher comum, disse Mooshum, boa em algumas tantas coisas - tecer redes, apanhar coelhos, tirar e curtir o couro. Gostava de fígado de veado. Chamava-se Akiikwe, Mulher da Terra, e, como dizia seu nome, era uma pessoa sólida" (ERDRICH, 2014, p.183). Joseph conta em seu sonho que ela e seu marido nunca foram mesquinhos e que, mesmo em invernos rigorosos, conseguiam buscar alimento para sua família, fato que muda quando os indígenas da terra são colocados dentro das reservas.

Por meio do sonho, Joseph conta que após a aglomeração dos indígenas nas reservas, alguns indígenas detinham um pedaço de terra, assim como o homem branco, mas que seriam necessários vários anos para que aquelas terras pudessem sustentar aquele povo durante o inverno. Diante da falta de alimentos, Akii abre um buraco no gelo para que possam se alimentar dos peixes, até o dia em que um deles disse a ela: "meu povo vai dormir agora e você vai passar fome" (ERDRICH, 2014, p.184). Os peixes eram o pouco alimento que ainda restava para sua sobrevivência no inverno tão rigoroso, mas que agora se recusavam a oferecer suas vidas para o sustento dos Anishinaabes. Akii nos mostra que nesses tempos de fome, algumas pessoas ficaram possuídas e transformavam-se em um wiindigoo, uma criatura "que podia lançar seu espírito para dentro de uma pessoa" (ERDRICH, 2014, p.184). Segundo Akii, um wiindigoo faria com que uma pessoa tornasse um animal e "veria seus irmãos humanos como carne de caça" (ERDRICH, 2014, p.184).

Mirage, seu esposo, ao olhar para Akii, acredita que sua esposa está no processo de transformação em um wïndigoo, pois imaginou que seus olhos estavam a brilhar no escuro. Na cultura Anishinaabe, a primeira coisa a ser feita diante da aparição de um wiindigoo é matá-lo imediatamente, entretanto, deve-se chegar a um acordo comunitário sobre sua morte, uma vez que há uma maneira certa para que tal ato seja feito. Após reunir os homens da tribo, seu esposo convence os homens de

4 Em itálico no original. 
que sua esposa será uma ameaça para eles, pois "ela havia cortado o braço para que a criança bebesse o sangue, então o bebê poderia estar se tornando um wïndigoo também" (ERDRICH, 2014, p.184). Ao tentarem amarrá-la, ela luta, sendo necessária a presença de seis homens para contê-la.

Isso posto, os homens da tribo decidem, então, que ela precisa ser morta para a salvação de seu povo. Porém, segundo a tradição, a única pessoa que poderia matar um wiindigoo seria alguém que compartilhasse o mesmo sangue. Entretanto, se seu marido a matasse o povo Akiikwe buscaria por vingança diante de sua morte. Uma vez que suas irmãs se recusaram a matá-la, a única solução seria seu filho. Diante dessa única solução, os homens "deram uma faca para o menino e o mandaram matar a mãe. Ele tinha doze anos. Os homens a seguraram. Ele deveria cortar o pescoço dela. $\mathrm{O}$ menino começou a chorar, mas disseram-lhe que ele tinha que fazer aquilo de qualquer jeito. O nome dele era Nanapush" (ERDRICH, 2014, p.185).

Ao tentar fugir com sua mãe, uma vez que acreditava na incapacidade de sua mãe o ferir, eles são pegos pelos homens da tribo, que prendem Akii novamente. No mesmo buraco onde Akii abriu para que pudesse pescar, os homens a colocam para ficar presa, dentro da água congelante. Nanapush ficou ao seu lado, "no gelo ali e cantou a canção da morte dela" (ERDRICH, 2014, p.185).

Ao ver seu pai, Nanapush pede a ele uma arma, declarando que mataria sua mãe, caso ela decidisse sair do buraco, o que de fato ela fez. Porém, Akii é uma sobrevivente, "Assim que os homens saíram de vista, Akii quebrou o gelo com a cabeça para sair. Ela conseguiu se soltar da pedra e respirou o ar que fica logo abaixo da camada de gelo" (ERDRICH, 2014, p.185). Nanapush, ao invés de impedi-la, decide acompanhá-la em uma fuga, o que os torna exilados da tribo. Após encontrarem abrigo e acenderem uma fogueira, Akii conta ao filho que

enquanto esteve debaixo da água, o peixe falou com ela e se desculpou e disse que ela precisava de uma canção de caça. Ela cantou essa canção para o filho. Era uma canção de búfalo. Quando o búfalo se aproxima dos lagos e dos rios, nos dias quentes de verão, eles soltam seus carrapatos gordos na água para os peixes comerem, e sua bosta atrai outros insetos que os peixes também apreciam. Eles gostariam que o búfalo voltasse. Perguntaram-me para onde o búfalo tinha ido, disse Akii. Eu não sabia responder. O menino aprendeu a canção, mas disse que achava que era inútil. Ninguém via um búfalo havia anos (ERDRICH, 2014, p.186).

Após acordarem com fome e cientes de que seria mais fácil morrer do que continuar nessas condições, Nanapush, com os arames que tinha consigo, monta uma armadilha para que possa caçar algum animal que os possa alimentar. Feita a armadilha, voltaram a dormir e, quando acordaram, viram um coelho preso em sua armadilha. Sua mãe arrasta-se até o animal para ver o que ele dizia, e o leva para seu filho. Akii, então, diz a seu filho que o coelho se entregou para que eles pudessem 
se alimentar, mas pediu que seus ossos fossem jogados na neve para que pudesse voltar a viver, fato que nos mostra também a vida como um processo circular, um nascer, morrer e nascer. Nanapush, então, come o coelho e oferece à sua mãe, que se nega a comê-lo, escondendo seu rosto para que Nanapush não o visse. Sua mãe diz a Nanapush que ouvira a mesma canção que o peixe lhe ensinou, dizendo que,

O búfalo sempre revirava a terra, de forma que grama crescia melhor para os coelhos comerem. Todos os animais sentem falta do búfalo, mas também sentem falta dos verdadeiros Anishinaabeg. Pegue a arma e viaje direto para o oeste. Um búfalo voltou lá daquele horizonte (ERDRICH, 2014, p. 187).

Assim, Joe segue para o oeste para que possa ter um encontro com o búfalo, que lhe ensinará grandes lições. Ao perseguir seus rastros por algum tempo, Nanapush chega até o animal e observa que, de fato, era uma búfala "tão demente e decrépita quanto Nanapush viria a ser, e eu, e todos os sobreviventes daqueles anos, os últimos de tantos" (ERDRICH, 2014, p. 189). Essa história da búfala e Nanapush tem muito a nos mostrar, principalmente sobre a construção simbólica da identidade dos indígenas Chippewa, como veremos nas próximas páginas. Assim, a mulher não apenas sobrevive, mas indica o caminho da sobrevivência para seu povo, iniciando o caminho por seu filho, e sendo auxiliada pela terra e pelas criaturas que vivem nela. Essa relação com a natureza, tanto cultural quanto mítica e simbólica, vai ser ilustrada pela presença da búfala.

\section{DUAS MULHERES, DUAS HISTÓRIAS}

Ao compararmos as histórias de Akii e de Geraldine, vemos que elas apresentam muito em comum, e que suas configurações representam dois momentos históricos dos povos Chippewa, que de uma forma cíclica continuam a acontecer. Assim como Nanapush, Joe permanece fiel à sua mãe e busca por justiça contra a violência que deixara marcas não apenas em sua mãe, mas em sua família e comunidade. Diferente dos personagens Bazil e Mirage, esposos de Geraldine e Akii, respectivamente, que se apresentam passivos diante das situações postas a eles, até mesmo coniventes com os erros cometidos contra as mulheres. Bazil sente-se impotente diante da grande muralha imposta pelo sistema legal ao qual eles estão submetidos, e Mirage sujeito às regras da tradição, que exigia que o wïndigoo fosse morto, nada fazendo para tentar salvar sua esposa.

Nas duas histórias há a presença de um wiindigoo, que, ao olharmos sutilmente, se apresentam estruturalmente na mesma configuração. No sonho de Mooshum, quando analisadas as duas narrativas em uma perspectiva histórica, não é Akii que se apresenta como um wiindigoo, mas o próprio sistema colonial que desapropriou os 
indígenas de suas terras, colocando-os em reservas, privando-os de seu contato com a terra e, principalmente, de alimentação. Esse momento da história de Erdrich é visto como, segundo Hobsbawm (2012, p.408), um contexto de uma "população indígena comparativamente fraca, além de regiões que os colonos puderam virtualmente tratar como uma terra de ninguém, e da qual simplesmente eliminaram os índios" (HOBSBAWM, 2012, p.408).

Akii, no sonho de Mooshum, nos mostra que agentes do governo prometeram ao povo suprimentos para que a perda da terra fosse compensada, entretanto, essa promessa nunca foi cumprida. Por consequência, Akii relata que diante dessa situação eles deixaram as fronteiras e seguiram de volta para o Canadá, "mas os caribus havia muito tinham desaparecido, não sobrou nenhum castor, nem sequer um rato almiscarado. As crianças choravam e o velho cozinhava tiras de suas calças de couro de alce para mastigarem" (ERDRICH, 2014, p.184). Joe deixa claro, durante a obra, estar ciente dessa carga histórica sofrida por ser povo, pois sabe que "durante anos, o nosso povo lutara para resistir a uma incansável hoste de seres gananciosos e imprevisíveis. Nosso exército se reduzira a uns poucos guerreiros desesperados e nós estávamos desarmados e com fome. Vivíamos a proximidade da derrota” (ERDRICH, 2014, p.115).

Com isso, Akii, no sonho de Joseph (Mooshum), deixa claro como foram os primeiros anos na reserva, um local onde "eles nos espremeram" (ERDRICH, 2014, p.188). Pela história de $A$ kii, Joe tem ciência de que seu povo passou fome "enquanto as vacas dos colonos engordavam nos pastos cercados de nossas antigas regiões de caça (...) foram anos ruins. Nanapush viu sua gente passar fome e morrer" (ERDRICH, 2014, p.188). É nesse contexto histórico de aglomeração dos povos indígenas nas reservas que o mito do wiindigoo cria maior ênfase na cultura indígena, uma vez que a fome se acentuou na comunidade, fazendo com que milhares de indígenas morressem.

É nesse período também que os búfalos, grande símbolo para os indígenas, foram quase extintos pelos colonos europeus. Isso fica marcado no sonho de Mooshum ao dizer que "alguns velhos diziam que os búfalos haviam desaparecido num buraco na terra. Outros tinham visto os homens brancos atirando em milhares deles de dentro de um vagão, deixando-os apodrecer" (ERDRICH, 2014, p.189). Muitos colonizadores brancos tinham a caça dos búfalos como esporte e, no ano de 1875, cerca de 9 milhões de búfalos já haviam sido mortos, fazendo com que seu número caísse drasticamente à quase extinção. Isso afetou diretamente a alimentação dos povos indígenas, bem como a ausência de material para a fabricação de suas roupas e abrigos que provinham principalmente desses animais, na maioria das tribos do Norte. Nesse período da história dos indígenas, por volta do ano 1867, período em que foram obrigados a se mudarem para as reservas, houve grande resistência por boa parcela da população indígena, gerando assim 
grandes conflitos entre brancos e índios, que acabou por culminar no massacre de Wounded knees.

Na história de Geraldine, seu estupro acontece na casa redonda, local sagrado construído por Nanapush, conforme a búfala o instruiu a fazer. Nesse ponto a casa redonda representa o sagrado, a cura e principalmente a maneira pelo qual os indígenas buscariam por Justiça. Ao comparar a violência de sua mãe e a história de Akii, Joe percebe que Linden também pode ser considerado um wiindigoo, um ser que devora as pessoas e deixa um rastro de sofrimento por onde passa. Por esse motivo, Joe determina-se a buscar a seu modo a justiça para sua mãe, como Nanapush fez por Akii.

A figura do Wiindigoo é familiar para os povos indígenas, predominante nas literaturas Anishinaabe (Ojibwe) e Cree, comumente apresentado como Windigo, Wendigo ou Witiko. Windigo é uma criatura mitológica de alguns povos indígenas estadunidenses e canadenses, cujo apetite insaciável por carne humana nunca pode ser satisfeito. Além desse desejo desenfreado por carne humana, o Wiindigoo também tem o poder de transformar seres humanos em canibais, fazendo com que eles sofreram da mesma voracidade. Segundo Kimmerer (2013), em seu capítulo Windigo Footprints do livro Braiding Sweetgrass,

O Windigo é o lendário monstro do nosso povo Anishinaabe, o vilão de uma história contada em noites geladas na floresta do norte. Você pode senti-lo espreitando atrás de você, um ser na forma de um homem desproporcional, com três metros de altura, com cabelos brancos como gelo pendurados em seu corpo trêmulo. Com braços como troncos de árvores, pés do tamanho de raquetes de neve, que facilmente viaja através das nevascas do tempo da fome, nos perseguindo. O hediondo fedor do seu hálito de carniça envenena o cheiro limpo de neve que se forma atrás de nós. Presas amarelas pendem de sua boca que está em carne viva, porque ele mastigou seus lábios por fome. Mais revelador de tudo, seu coração é feito de gelo 6 .

5 O Massacre de Wounded Knee ocorreu em 29 de Dezembro de 1890 em Dakota do Sul, e é considerado o último grande conflito entre o Exército dos EUA e os indígenas americanos. Foi uma batalha em que a esmagadora força de soldados estadunidenses matou mais de 300 homens, mulheres e crianças indígenas Lakota. Esse massacre foi uma retaliação à batalha de Little Bighorn, que ocorreu em 25 de Junho de 1876, ano do centenário de independência dos Estados Unidos da América. Naquela batalha, a Sétima cavalaria estadunidense, comandada pelo General Custer, foi derrotada pelos grupos indígenas Lakotas e Cheyennes do Norte, sob o comando dos lendários líderes indígenas Touro Sentado e Cavalo Louco.

6"The Windigo is the legendary monster of our Anishinaabe people, the villain of a tale told on freezing nights in the north woods. You can feel it lurking behind you, a being in the shape of an outsized man, ten feet tall, with frost-white hair hanging from its shaking body. With arms like tree trunks, feet as big as snowshoes, it travels easily through the blizzards of the hungry time, stalking us. The hideous stench of its carrion breath poisons the clean scent of snow as it pants behind us. Yellow fangs hang from its mouth that is raw where it has chewed off its lips from hunger. Most telling of all, its heart is made of ice" (KIMMERER, 2013). 
A presença do Wiindigoo na obra de Erdrich explora as tensões sociopolíticas de contato entre brancos e a cultura indígena, evidenciando a conexão entre a proliferação de Wiindigoo e o processo de colonização, uma vez que os povos indígenas foram afetados pela diminuição de recursos e doenças mortais introduzidas pelos colonos europeus. Seguindo essa cadeia de raciocínio, a fome gerou o Wüindigoo e a colonização causou fome; portanto, a colonização trouxe o Wiindigoo à existência. Kimmerer (2013), afirma que figura como o wiindigoo representa o medo coletivo e seus valores, uma vez que ele é "nascido de nossos medos e nossas falhas, Wiindigoo é o nome para o que está dentro de nós, que se preocupa mais com sua própria sobrevivência do que com qualquer outra coisa" (KIMMERER, 2013)7.

Linden, figura que representa o wiindigoo no livro de Erdrich, é da família Lark, que segundo Bazil são "o tipo de gente que trata cordialmente os 'bons índios', a quem desprezam na intimidade e com quem são condescendentes aos olhos públicos, de maneira a aprovar seu amor pelos índios, enquanto se dedicam a enganá-los" (ERDRICH, 2014, p.55). E não apenas isso, o estupro praticado por Linden contra Geraldine não foi feito apenas pela fome sexual, mas pela fome de poder. Ele quer coagi-la a parar de investigar um outro caso, de roubo, chantagem e, por fim, de assassinato, além dos documentos comprobatórios. Assim, a fome de Linden abrangia todos os tipos de apetites escusos, incluindo a ganância e a luxúria.

Embora Linden e Linda sejam irmãos gêmeos, apenas Linden se torna essa figura maléfica, uma vez que esteve mais próximo de sua mãe, que segundo Linda, "tinha o seu jeito para incitar a violência emocional. Outras pessoas absorveram seu ódio. Era uma senhora branca pequena, de aspecto frágil. Mas seu sentido de direito era contagiante. Era venenosa. Talvez Lark tenha esquecido tudo isso, ou talvez tenha absorvido o veneno dela" (ERDRICH, 2014, p.58). Enquanto Linda apresenta apenas o seu exterior "magneticamente feio. Com seu rosto mortiço em forma de cunha” (ERDRICH, 2014, p.104), Linden é quem herdou toda a maldade e ódio da mãe, que o fez se tornar um wïndigoo, uma vez que, para Linda, sua mãe biológica "teria que voltar sua fúria contra si mesma, sua vergonha, sobre outra pessoa - a criança que escolhera. Ela teria culpado Linden, transferido suas raivas distorcidas para ele" (ERDRICH, 2014, p.127). Bazil destaca que os Larks são como muitos outros que enganam seu povo, como 'empresários desastrosos', que, segundo ele,

Enquanto seus padrões morais para o resto do mundo eram rígidos, sempre conseguiam achar desculpas para suas próprias falhas. São essas pessoas, na verdade, disse meu pai, hipócritas do cotidiano, que são capazes, em situações especiais, de atos monstruosos, se tiverem a oportunidade (ERDRICH, 2014, p.55).

A fome, a colonização e as imposições patriarcais do homem branco geraram violência tanto contra Geraldine quanto contra Akii, ou seja, no nível simbólico e

7 "Born of our fears and our failings, Windigo is the name for that within us which cares more for its own survival than for anything else" (KIMMERER, 2013). 
mítico e, também, no plano físico, no tempo presentificado. As duas mulheres indígenas foram forçadas e quase perderam suas vidas por tentarem proteger seu grupo étnico. Nessa equação do feminino mítico em contraponto ao feminino real, temos também a figura da búfala, mítica e simbólica, que pratica o sacrifício pelo povo indígena, assim como Geraldine e Akii.

Geraldine começa o processo de autocura pela palavra - quando ela fala, admite ao marido, que foi estuprada. "Ela falou num tom baixo, rouco, que retumbou dentro da minha cabeça. Fui estuprada, Bazil. Meu pai não se mexeu, não segurou sua mão, nem ofereceu nenhum tipo de conforto. Parecia congelado. Não existe prova alguma do que ele fez. Nenhuma. A voz da minha mãe era um gemido (ERDRICH, 2014, p.148)."

\section{GERALDINE E A BÚFALA E SUAS HISTÓRIAS ENTRELAÇADAS}

Geraldine e a búfala também são dois pontos semelhantes nessas duas histórias. A búfala é descrita por Joe, a partir do sonho de seu Mooshum, como uma criatura que "não passava de um couro pendurado sobre os ossos saltados. Ainda assim, ela já fora imensa e, em seus olhos marrons, havia uma tristeza profunda que abalou Nanapush, mesmo em todo seu desespero" (ERDRICH, 2014, p.189). Descrição semelhante também pode ser vista quando Joe descreve sua mãe durante seu confinamento no quarto:

Estiquei a mão para acender sua luz de cabeceira - ela não queria abrir O rosto era uma mancha pálida no ar opaco e seus traços estavam marcados pelo cansaço. Ela perdera todo o peso, apenas ossos saltados. Os dedos apertaram meus braços com força. A voz estava rouca, como se tivesse recém-acordado. (...) dava para ver sua espinha nitidamente através da camisola fina, os ombros pareciam dois nós. Os braços haviam se transformado em graveto (ERDRICH, 2014, p.91).

As duas figuras, Geraldine e a búfala, são marcadas no livro de Erdrich como a invisibilidade dos povos indígenas perante as leis de garantia de direitos e justiças em solo estadunidense e o sofrimento decorrente da violência e da perda das raízes, da tradição e da comunidade. A primeira representa o sofrimento dos primeiros momentos da dominação europeia, e a segunda simboliza a perpetuação e a reverberação do processo de colonização e da violência contra a mulher etnicamente marcada. Nesse sentido, Hobsnbawn (2012, 2012, p. 405) afirma categoricamente que "não se pode negar, nem negligenciar, que o impacto da conquista e das explorações sobre essas populações foi catastrófico, e não só durante os 150 primeiros anos de conquista europeia" aos indígenas em geral, mas principalmente às mulheres indígenas, duplamente colonizadas, uma vez que, além de não serem brancas, ou 
seja, no mesmo nível dos grupos colonizadores, também eram consideradas como seres à disposição dos ataques dos homens brancos, caminho para sua luxúria e para o trabalho escravo. Os níveis de violências contra mulheres não brancas mostram uma intersecção existente entre raça e gênero, que não pode ser desprezada.

Desse modo, ao matar a búfala, Nanapush entristece-se por saber que ela "conseguiu sobreviver com determinação e coragem, mesmo que sua gente tenha sido destruída. Você deve ter se tornado invisível” (ERDRICH, 2014, p.19o). Geraldine também sofre esse processo de invisibilização para a sobrevivência e a cura, quando se tranca em seu quarto, pois teme as retaliações de Bazil contra o branco opressor que a estuprou, além do medo das ameaças feitas por ele. Para que nada acontecesse com sua família, ela se isola em seu quarto, sendo condicionada ao silêncio, fazendose dessa forma, invisível.

Geraldine trabalhava no escritório tribal, cuja função era "conhecer os segredos de todo mundo" (ERDRICH, 2014, p.153), sendo ela a pessoa que detinha o controle das "listas originais dos recenseamentos feitos na área que se tornou a nossa reserva remontam a 1879 e incluem uma descrição de cada família por tribo, frequentemente por clã, ocupação, relacionamento, idade e nome original em nossa língua” (ERDRICH, 2014, ERDRICH, 2014, p.153). Segundo Joe, sua mãe era responsável pela parte documental que registrava os nascimentos das crianças indígenas, fato que a levou à casa redonda a pedido de Mayla, pois Linden deseja ter acesso aos arquivos sobre Mayla e seu bebê. Diante disso, enquanto a búfala magra e com ossos à vista representam a invasão colonial nas terras indígenas, e a extrema fome à qual os indígenas foram expostos, Geraldine, com sua extrema magreza, também simboliza as diversas formas de aniquilação de suas tradições, cultura, os diversos assédios e estupros sofridos por mulheres indígenas, cujos filhos eram de "incesto, assédio, estupro, adultério, fornicação ou dentro dos limites da reserva, filhos de fazendeiros brancos, de banqueiros, de freiras, de superintendentes do Departamento de Assuntos Indígenas, de policiais e de padres" (ERDRICH, 2014, p.153). Também representa a violação contra o corpo da mulher indígena. Ou seja, frutos de todas as ações que os indígenas sofreram no processo de colonização e destruição de suas terras, e que até os dias de hoje se fazem presente na vida dos primeiros povos. O excerto também mostra a situação frágil que diferencia mulheres não brancas de classe pobre, colocando em relevo a importância de se trabalhar o gênero na intersecção entre raça, cultura, classe social, entre outros, quando obras como como A Casa Redonda são estudadas.

A búfala pede que se construa a casa redonda e, ao mesmo tempo, sacrifica-se pela vida do povo indígena. Da mesma forma, Geraldine é sacrificada por meio do estupro e da ameaça na casa redonda, por negar a Linden o acesso aos papeis que ele exige, e para manter silencio com relação ao assunto, para proteger a população indígena do ataque de Linden (o Windigoo personificado). O círculo também se torna um símbolo feminino, e representa os ciclos de vida e morte. Ao mesmo tempo que a casa redonda simboliza o sagrado para Joe, a casa redonda é também o local da extrema violência contra sua mãe, Geraldine. Quando Joe pensa sobre a 
casa redonda, ele sente que ela representa uma "parte de algo maior, uma ideia, uma verdade, mas apenas um fragmento. Não via o todo, apenas uma sombra daquele estilo de vida" (ERDRICH, 2014, p.219). Isso sugere que, enquanto a casa redonda representa a riqueza da cultura Chippewa, suas tradições e cura do fardo histórico ao qual foram sujeitados, parte dessa cultura também tornar-se uma ausência: ou seja, o vazio da cultura que foi violentamente reprimido, com suas terras e suas ligações com seu espaço e com tudo que nele há. Ao mesmo tempo, trata-se da profanação do sagrado indígena e da mulher indígena.

A casa redonda, portanto, na obra de Erdrich, é um monumento à memória das partes da cultura Chippewa que foram violentamente destruídas. A casa redonda é construída para ser lembrada como o ventre da búfala, que representa o gerar, a santidade e o renascimento, desse modo, um dos piores crimes que poderia acontecer nesse local é o de estupro, que é duplamente simbólico, uma vez que é a invasão do corpo cultural e do corpo sagrado da mulher e da cultura indígenas.

A búfala branca presente na obra é conhecida entre os Lakotas, mas também em outras tribos indígenas, como White Buffalo CalfWoman, ou também Pte Ska Win ou Ptesanwi. Essa figura do sistema mitológico indígena que é conhecida por trazer mensagens e a sabedoria dos antepassados, mas, principalmente, é considerada uma curadora, que vem para ajudar aqueles que se encontram em dificuldade no momento maior necessidade. Em $A$ casa redonda, temos a presença da búfala restaurando o sentido de justiça para os indígenas, que é concretizado na própria construção da casa redonda, a forma do útero do nascimento de uma cultura e, ao mesmo tempo, o eixo em torno do qual o universo se organiza. A búfala, que anteriormente reuniu o povo, agora, em um momento de grande dificuldade, volta para trazer o senso de justiça e, principalmente, da cura e resistência diante da ameaça do colonizador. Para a búfala, as antigas regras os forçavam a trabalhar juntos, e, ao trazer a criação da casa redonda, ela dá ao povo indígena o símbolo para que eles possam voltar a se unir e resistir a invasão de seu território.

Muitas histórias estão associadas à figura de White Buffalo Calf Woman, e todas elas apresentam um significado para a comunidade indígena. As lendas contam que houve um tempo em que as pessoas perderam a habilidade de se comunicar com o Criador. Então, o Criador enviou a sagrada Mulher para ensinar as pessoas a rezar com o cachimbo. Com esse cachimbo, sete cerimônias sagradas foram dadas ao povo, para que desse modo, o povo pudesse encontrar um futuro com harmonia, paz e equilíbrio.

Em uma das lendas que narram a história dessa figura do sistema mitológico indígena, conta-se que há muito tempo, dois jovens estavam caçando quando, de repente, veio uma linda donzela vestida de pele de gamo branca. Um dos caçadores olhou para ela e a reconheceu como uma Wakan, ou um ser sagrado, e desviou os seus olhos. O segundo caçador aproximou-se dela com desejos sexuais e com luxúria em seus olhos. A White Buffalo Calf Woman chamou este caçador, que se aproximou dela. Ao chegar até ela, uma nuvem de poeira surgiu ao redor dos caçadores, fazendo com que ficassem cobertos por aquela nuvem. Assim que a nuvem de poeira baixou, 
nada além de uma pilha de ossos estava ao lado dela. A nuvem consumiu o corpo daquele caçador que a olhou com desejos carnais, desrespeitando-a. Em seguida, ela caminha em direção ao respeitoso jovem caçador e explica a ele que ela tinha apenas cumprido o desejo do outro jovem, permitindo-lhe, naquele breve momento, viver uma vida inteira, morrer e decair. White Buffalo Calf Woman instruiu o jovem respeitoso a voltar ao povo e dizer-lhes que se preparassem para a sua chegada, pois ela os ensinaria a orar. Dessa maneira, a mulher sagrada vai até os homens e lhes presenteia com o cachimbo sagrado, ensinando-as sete maneiras sagradas de orar. Com essa narrativa, vemos que a sacralidade para os indígenas é de extrema importância e que, para aqueles que atacam ou tentam manchar o seu simbolismo, como é visto com o personagem Linden, a destruição é a única alternativa. Nesse sentido, a casa redonda, que como foi narrado por Joe, tinha um lamento que "parecia brotar da própria estrutura" (ERDRICH, 2014, p.63), clama para que a justiça seja feita. Ou seja, quando a morte de Linden é concretizada, a justiça do povo Anishinaabe, que tem como símbolo a figura da casa redonda, é restaurada.

Nesse mesmo significado, a história de Nanapush, que ocupa dentro do texto de Erdrich o papel de Trickster, desempenha uma das funções mais características desse personagem, que são os ensinamentos por meio das histórias. Suas histórias ensinam ao povo indígena habilidades de sobrevivência e de como estabelecer a ordem em meio ao caos. Essas histórias, tanto na narrativa oral, quanto na escrita (como é no caso de autores que se utilizam dessa função) podem ser carregadas de humor ou de alto nível de seriedade, como nas histórias que narram momentos sagrados, que podem ser vistos na criação da casa redonda. Desse modo, tanto a búfala quanto Akii apresentam-se na obra como dois personagens que, juntos, trazem ao povo Anishinaabe ensinamentos e meios de resistência às ações dizimadoras daqueles que buscavam destruí-los, restaurando, assim, seu sistema de justiça, assim como Geraldine, a mulher que se recolhe ao silêncio e tem capacidade de sobreviver e resistir, autocurar-se e, ao fazê-lo, ajuda na restauração da justiça.

\section{CONCLUSÃO}

Louise Erdrich, em companhia de um grupo de outros escritores e, principalmente escritoras indígenas estadunidenses, por sua recepção no cenário literário e pelo sucesso de suas publicações, tem o poder de evidenciar a história e a presença da mulher indígena etnicamente e racialmente marcada, na construção da identidade estadunidense, dando espaço a essas vozes antes silenciadas.

No corpo de sua obra, principalmente com relação a sua tribo Chippewa, Erdrich destaca os efeitos das políticas e negligência que os indígenas estadunidenses viveram com os primeiros colonos europeus e que ainda continuam a enfrentar diariamente, principalmente em temas como violência, abuso sexual, acesso à justiça e território. De uma forma simbólica densa, o ataque ao território e ao sagrado indígena 
é demonstrado pelo estupro da mulher. A terra, a mulher e a búfala não apenas representam o sofrimento da mulher indígena e da população indígena em geral, mas também sua sacralidade, e sua resistencia, uma vez que Akii, juntamente com o filho Nanapush salva seu povo, mesmo depois de ter sido atacada e quase morta por eles. O windigoo, o mal que ataca essas mulheres toma diversas formas no decorrer da narrativa, mas é sempre a ganância e a fome que não são aplacadas. Mostra bem a forma da sociedade patriarcalista e racista ao mesmo tempo em que questiona e problematiza a história e a opressão, assim como combate os estereótipos da visão sobre os povos indígenas e, especialmente, sobre a mulher indígena. Dessa maneira, a escritora cria um retrato de uma tribo contemporânea que evidencia a destruição de seus modos de vida e sua resistência diante dos problemas e das condições a eles impostas.

Isso posto, podemos afirmar que a narrativa de Erdrich contra a violência - o foco central do romance - é bastante convincente para evidenciar os abusos sofridos por essa população, que são vistos e, muitas vezes, negligenciados pela lei. Nesse sentido, ela demonstra o poder da escrita e da literatura feminina indígena, fazendo do leitor uma testemunha histórica, levando-o a considerar as complicações legais, a história social e os efeitos devastadores da violência contra os povos indígenas e da violência perpetrada pelo homem branco contra a mulher indígena (Mayla, assassinada e apenas citada, e Geraldine, a sobrevivente e resistente).

Diante desses fatos, percebemos que os elementos (simbólicos, míticos e sociais) apresentados na obra possuem papel fundamental para a Literatura Indígena, pois é por meio desses elementos que esses povos constituem suas identidades e manifestam suas marcas culturais e espirituais, além de demonstrarem a força de sobrevivência da mulher indígena.

\section{REFERÊNCIAS}

AHMAD, Aijaz. Linhagens do Presente. Ensaios. 1.ed. Tradução Sandra Guardini Vasconcelos. São Paulo: Boitempo, 2002.

ERDRICH, Louise. A Casa Redonda; tradução Daniel Estill - $1^{\underline{a}}$ ed. Rio de Janeiro: Objetiva, 2014.

ANZALDÚA, Gloria. Speaking in tongues: a letter to Third World women writer. In: MORAGA, Cherríe \& ANZALDÚA, Gloria (orgs.). This bridge called my back: writings by radical women of color. New York: Kitchen Table, 1981.

HOBSBAWM, Eric. Pessoas Extraordinárias: resistência, religião e jazz. Tradução: Irene Hirsch, Lólio Lourenço de Oliveira. São Paulo: Paz e Terra, 1998

KIMMERER, Robin Wall. Braiding Sweetgrass. Minneapolis: Milkweed, 2013. 